\title{
Renal Agenesis
}

National Cancer Institute

\section{Source}

National Cancer Institute. Renal Agenesis. NCI Thesaurus. Code C99041.

A congenital abnormality characterized by the absence of one or both kidneys. 